\title{
ABUNDANCIA, DENSIDAD, PREFERENCIA DE HÁBITAT Y USO LOCAL DE LOS VERTEBRADOS EN LA TUZA DE MONROY, SANTIAGO JAMILTEPEC, OAXACA
}

\author{
IVÁN LIRA TORRES \\ Consultor del Programa Bosques Mexicanos: Selva Zoque \\ Fondo Mundial para la Naturaleza (WWF-México) \\ 2a Norte Oriente 1923, Depto. 6. Residencial Los Quezales, Tuxtla \\ Gutierrez, Chiapas, C.P. 29040 \\ ilira_12@hotmail.com
}

\begin{abstract}
Resumen: Se evaluó la abundancia relativa, la densidad poblacional y la preferencia de hábitat de los vertebrados en la Tuza de Monroy, Santiago Jamiltepec, Oaxaca, mediante encuestas y observaciones, así como su utilización por los pobladores. Los índices de abundancia y densidad de las especies abundantes de la localidad fueron: Odocoileus virginianus, 1.29 rastros $/ \mathrm{km}$ y $4.33 \mathrm{ind} / \mathrm{km}^{2}$; Tayassu tajacu, 0.55 rastros $/ \mathrm{km}$ y $1.98 \mathrm{ind} / \mathrm{km}^{2}$; Nasua narica, 0.19 rastros $/ \mathrm{km}$ y $16.93 \mathrm{ind} / \mathrm{km}^{2 ;}$ Leopardus pardalis, 0.06 rastros $/ \mathrm{km}$ y Ctenosaura pectinata, 0.20 rastros $/ \mathrm{km}$ y $6.87 \mathrm{ind} / \mathrm{km}^{2}$. La vegetación secundaria fue el hábitat más utilizado por las cinco especies $(P<0.01)$. La cacería en la zona es persistente debido a que su carne es utilizada como alimento o para la venta, y a veces se utiliza para controlar el daño a sus cultivos. Se sugiere que la permanencia de estas especies dependerá de la disponibilidad de alternativas económicas en la localidad, entre las que se destaca la implementación de Unidades de Conservación, Manejo y Aprovechamiento Sustentable de la Vida Silvestre (UMA), entre otras.
\end{abstract}

Palabras Clave: Estimación poblacional, vertebrados, cacería, Región Terrestre Prioritaria del Bajo Río Verde, Oaxaca.

Abstract: Indices of relative abundance, density, habitat use, and the impact of hunting were evaluated for the vertebrates of La Tuza de Montoy, Santiago, Jamiltepec, Oaxaca. The estimations were made through observations on line transects as well as through interviews. The relative abundance indices and density estimated of the more abundant species were: Odocoileus virginianus, 1.29 signs $/ \mathrm{km}$ and $4.33 \mathrm{ind} / \mathrm{km}^{2}$; Tayassu tajacu, $0.55 \mathrm{signs} / \mathrm{km}$ and $1.98 \mathrm{ind} / \mathrm{km}^{2}$; Nasua narica, 0.19 signs $/ \mathrm{km}$ and $16.93 \mathrm{ind} / \mathrm{km}^{2}$; Leopardus pardalis 0.06 signs/ $\mathrm{km}$ and Ctenosaura pectinata, $0.20 \mathrm{signs} / \mathrm{km}$ and $6.87 \mathrm{ind} / \mathrm{km}^{2}$. Secondary vegetation was the habitat mostly used by the five species. Hunting takes place in the area, mainly to obtain meat, as it is the main source of animal protein, for the bush - meat trade, or to control damage to crops. The permanence of these species in the area depends on implementing economic alternatives, like the establishment of conservation, management and sustainable use units of wild among others.

Key words: Population estimate, vertebrate, hunting, Región Terrestre Prioritaria del Bajo Río Verde, Oaxaca. 


\section{INTRODUCCIÓN}

La fauna silvestre de las selvas bajas caducifolias del Pacifico Oaxaqueño constituye un recurso natural para los habitantes locales. Numerosas especies de mamíferos, aves y reptiles han sido y siguen siendo aprovechadas con fines de alimento, vestimenta, medicina tradicional, herramientas, objetos rituales, símbolos, trofeos, y mascotas (González-Pérez et al., 2004; Ojasti, 2000; Robinson y Bennett, 2000; Shaw, 1991).

La importancia nutricional, económica y social de la fauna para los habitantes de las selvas caducifolias ha sido escasamente evaluada en términos cuantitativos, a pesar de que numerosas manifestaciones culturales como la gastronomía, la danza y la artes plásticas evidencian la relevancia de los animales silvestres en la región (Naranjo et al., 2004). Gran parte de las selvas del Pacifico Oaxaqueño han sido sometidas a un intenso uso agropecuario desde el inicio de la época colonial y hasta nuestros días. Muchas de estas áreas presentan una alta densidad humana, cuyas actividades económicas han provocado una elevada tasa de fragmentación y pérdida de los bosques tropicales secos que originalmente las cubrían (Laurance y Bierregaard, 1997; Ortiz-Pérez et al., 2004). Si bien la ganadería extensiva y la avicultura, así como los cultivos de maíz, fríjol, papaya, cacahuate, melón y sandia son actividades predominantes en las selvas caducifolias del Estado de Oaxaca, el uso de la fauna silvestre ha representado una fuente complementaria de alimento para sus pobladores. No obstante, la información disponible sobre actividades y uso de la fauna silvestre en la alimentación humana es muy escasa para este ecosistema.

Desafortunadamente, las prácticas de cacería no sustentables y la destrucción y fragmentación de las selvas caducifolias oaxaqueñas han originado cambios importantes en la distribución y la abundancia de numerosas poblaciones de fauna silvestre (Naranjo et. al., 2004). No todas las especies han sido igualmente afectadas, por un lado, la pava o cojolita (Penelope purpurascens), el ocelote (Leopardus pardalis), la iguana verde (Iguana iguana), el loro cabeza amarilla (Amazona oratrix) y el tapir centroamericano (Tapirus bairdii) han sufrido una severa declinación y aislamiento en sus poblaciones locales (Lira et al., 2005; Naranjo et. al., 2004), en contraste, la zorra gris (Urocyon cinereoargenteus), las chachalacas (Ortalis spp.) y la iguana negra (Ctenosaura pectinata) ha sido poco o nada afectadas por la transformación de los bosques maduros en sistemas agropecuarios y áreas de vegetación secundarias (Robinson y Bennett, 2000). Por lo anterior, los objetivos del presente estudio son: 1) estimar la abundancia, densidad y preferencia de hábitat de los vertebrados más frecuentemente aprovechados por los pobladores de la región; y 2) evaluar el uso local de las especies. 


\section{MATERIAL Y MÉTODOS}

\section{Área de estudio}

Este estudio se llevó a cabo en la localidad de Tuza de Monroy, municipio de Santiago Jamiltepec, ubicado al suroeste del estado de Oaxaca en la región costa $\left(16^{\circ} 03^{\prime} 03.0^{\prime \prime} \mathrm{N}\right.$ / 9751'45.0" W), limitada al sureste con el Parque Nacional Lagunas de Chacahua, al sur por el Océano Pacifico, al norte por la Sierra Madre del Sur y al oeste por el Río La Arena. El clima predominante es cálido subhúmedo con lluvias en verano (García, 1973). La precipitación varía entre los 500 a 1500 mm y con una temperatura media anual de $22 \mathrm{a} 34^{\circ} \mathrm{C}$, respectivamente (Arriaga et al., 2000). La vegetación predominante es la selva mediana subcaducifolia o bosque tropical subcaducifolio y la selva baja caducifolia o bosque tropical caducifolio (Rzedowski, 1998; Figura 1).

\section{Selección de sitios de muestreo}

El estudio se llevó a cabo entre agosto de 2004 y junio de 2005, el cual consistió en trabajo de campo durante nueve meses con salidas de seis días por mes. Se trazaron 10 transectos de 0.5 a $3.5 \mathrm{~km}$, seis fueron seleccionados en áreas con cacería moderada o nula y cuatro se ubicaron en áreas con cacería persistente. La longitud de cada transecto varió debido a que se intentó, en lo posible, que cada uno de ellos se ubicara dentro de un sólo tipo de hábitat: selva mediana subcaducifolia, selva baja caducifolia, vegetación secundaria y manglar (Lira et al., 2004). De acuerdo a los criterios de Furze et al. (1996) se realizó un listado preliminar de informantes clave con experiencia (cazadores de la zona); 12 en total, y posteriormente fueron contratados dos de ellos como guías de campo.

\section{Abundancia relativa}

Se realizaron observaciones directas y conteos de huellas y heces, empleando para su identificación guías de campo (Aranda, 2000). El criterio que se utilizó para la identificación de huellas fue la estructura anatómica, mientras que en el caso de las excretas se consideró forma, olor, tamaño y textura. Los conteos se realizaron entre las 08:00-17:00 h y el tiempo mínimo entre dos conteos en un mismo transecto fue de 20 días. Para evitar la sobreestimación de la abundancia se contaron como diferentes a grupos de rastros que tuvieran al menos una separación de 100 m entre sí, dado que la probabilidad de que sean del mismo individuo disminuye. En el caso de T. tajacu, los datos recabados fueron tomados considerando al grupo de individuos que conforman una piara en la localidad, no como indicador de presencia de un solo individuo. Los índices de abundancia relativa (AR) se calcularon con la siguiente ecuación (Naranjo, 2000). 
vol. 10
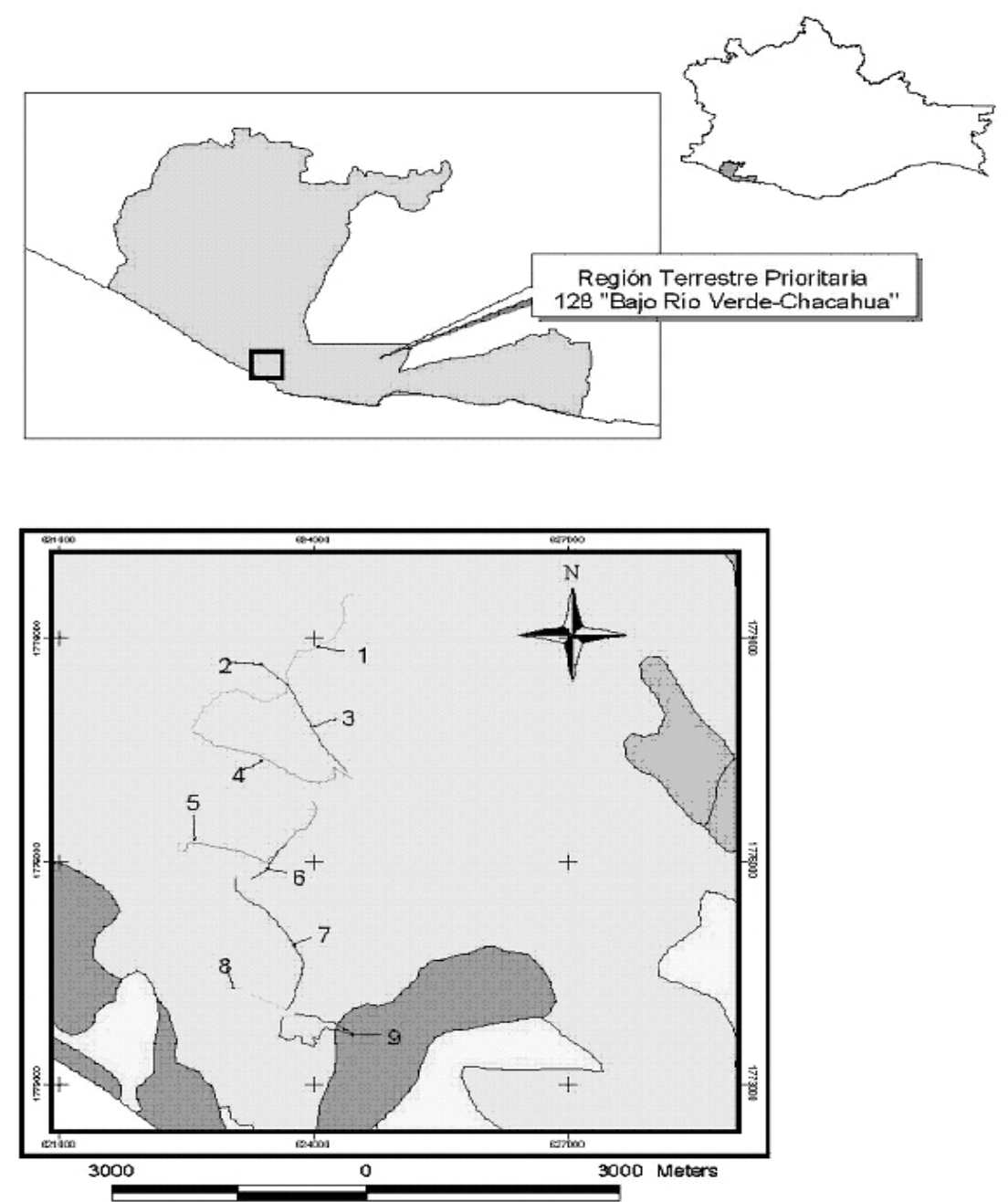

Figura 1. Localización del área de estudio en el Cerro de la Tuza, Costa de Oaxaca. Los senderos son: Casa de Piedra (1), Mixteco (5), Poza Verde (7), La Milpa (8). Los senderos con cacería moderada o baja son: Arroyo Catecuan (2), El Aguajote (3), Las Ánimas (4), sendero Tamandúa (6) y Cerro Tapír (9). $\square$ Selva Mediana Subcaducifolia, $\square$ Manglar, $\square$ Agricultura, $\square$ Cuerpo de Agua. 


$$
\mathrm{AR}=N r / L
$$

donde: $\mathrm{Nr}$ es el número de rastros observados y L la longitud (en km) de distancia recorrida.

Estos índices fueron calculados por cada transecto y mes, haciendo comparaciones por medio de una prueba de Kruskal-Wallis. Las variables estacionales (seca y lluviosa) y el impacto de la cacería (áreas con baja cacería vs áreas con cacería frecuente) fueron analizadas mediante la prueba de suma de rangos de Mann-Whitney. Todos los análisis estadísticos se realizaron con el programa SAS System para Windows Versión 6 (SAS, 1994) considerando una probabilidad de error del 0.05\%.

\section{Densidad poblacional}

Se hicieron observaciones directas anotando el número de animales visualizados con respecto a la distancia perpendicular y longitud del transecto. La densidad (D) se estimó mediante el método de Buckland et al. (1993), utilizando el programa Distance 5.0 Beta 3 (Thomas et al., 2005), el cual se basa en la aplicación de la siguiente fórmula:

$$
n A \times f(0) / 2 L
$$

donde: $n$ es el número de individuos observados.

A es el área de muestreo (en $\mathrm{km}^{2}$ ).

$L$ es la longitud del transecto.

$f(0)$ es la probabilidad de detección calculada a partir de las distancias perpendiculares de observación.

\section{Uso vs. disponibilidad de hábitat}

Se elaboraron mapas de la zona de estudio y de su cobertura vegetal con diferentes escalas gráficas a partir del Inventario Nacional Forestal 2000. El uso diferencial de hábitat se estimó mediante el modelo de Byers et al., (1984) el cual se basa en la prueba de Chi-cuadrada. Por medio del número de rastros (huellas y excretas) y observaciones directas se obtuvo la frecuencia observada, esperada y los intervalos de Bonferroni para cada tipo de cobertura vegetal utilizada por las especies, empleando el programa Habuse 4.0.

\section{Uso local de la fauna silvestre}

Se aplicaron cuestionarios estructurados a los cazadores del lugar con lo que se obtuvo información referente al número de animales observados, cazados o 
capturados por unidad de tiempo, partes anatómicas aprovechadas, así como sitios de captura y métodos preferidos de caza. Se incluyeron preguntas referentes a los daños causados a los cultivos por las especies consideradas en el estudio. El análisis de los resultados de las entrevistas se realizó tomando en cuenta el porcentaje de respuestas afirmativas de todos los entrevistados. También se llevó registro de animales consumidos por familia con la finalidad de obtener la biomasa extraída. Se recolectó el cráneo de las piezas cazadas, cada muestra llevó una etiqueta con la fecha, sitio exacto de captura y sexo del ejemplar. Los cráneos sirvieron para estimar la edad de cada individuo mediante la técnica de desgaste y reposición dentaria dentro de las siguientes categorías: cría, juvenil o adulto (Kirkpatrick y Sowls, 1962).

\section{RESULTADOS}

\section{Abundancia relativa}

Se recorrieron $217.8 \mathrm{~km}$ de transectos lineales de ancho variable, se observaron 598 rastros (huellas y excretas) de un total de quince especies de vertebrados con distribución y uso potencial por la comunidad (Cuadro 1). De éstos sólo se tomaron cinco especies, 301 (50.33\%; $1.29 \pm$ D.E. 0.98 rastros $/ \mathrm{km})$ correspondieron a Odocoileus virginianus, 120 (20.06 \%; $0.55 \pm 0.35$ rastros $/ \mathrm{km})$ a Tayassu tajacu, 44 ( $7.35 \% ; 0.20 \pm 0.11$ rastros $/ \mathrm{km})$ a Ctenosaura pectinata, 35 (5.85\%; $0.19 \pm 0.33$ rastros/ $\mathrm{km})$ a Nasua narica y 14 (2.34 \%; $0.06 \pm 0.08$ rastros $/ \mathrm{km})$ a Leopardus pardalis como las especies más representativas (Cuadro 2).

Los transectos con mayor abundancia de rastros para $O$. virginianus fueron: Las Ánimas con 3.10/km, El Aguajote con 2.39/km, Cerro Tapir con 2.16/km y Poza Verde con 1.39 / km; para T. tajacu: La Milpa con 1.11/km, Arroyo Catecuan con 0.97/ km, Las Ánimas con 0.76/km, Casa de Piedra con 0.73/km, Cerro Tapir con 0.58/km y Arroyo Mixtecos con 0.51/km; N. narica: La Milpa con 1.11/km, Arroyo Mixtecos con 0.27/km y Casa de Piedra con 0.24/km; L. pardalis: La Milpa con 0.27/km, Arroyo Mixtecos y Casa de Piedra con 0.11/km; y C. pectinata: Las Ánimas con 0.34/km, El Aguajote con 0.33/km, La Milpa con 0.27/km, Poza Verde 0.25/km, y Cerro Tapir con 0.23/km (Cuadro 2).

No hubo diferencias significativas en la abundancia relativa de las cinco especies dominantes de vertebrados entre sitios sujetos a cacería persistente y sitios con baja intensidad de caza (O. virginianus: $U=0.05$, gl=1, $P=0.818$; $T$. tajacu: $U=$ $0.528, \mathrm{gl}=1, P=0.468 ;$. narica: $U=2.241, \mathrm{gl}=1, P=0.134 ;$ L . pardalis: $U=0.591, \mathrm{gl}=$ 1, $P=0.442$; C. pectinata: $U=1.9333$, gl=1, $P=0.164$; Cuadro 3).

En el intervalo altitudinal entre los 0 y los $100 \mathrm{msnm}$ se observó abundancia relativa de rastros significativamente mayor para $O$. virginianus $(H=36.197, \mathrm{gl}=5$, $P<0.0001)$, T. tajacu $(H=9.413, \mathrm{gl}=5, P=0.043)$ y $N$. narica $(H=6.699, \mathrm{gl}=3, P=0.042)$. 


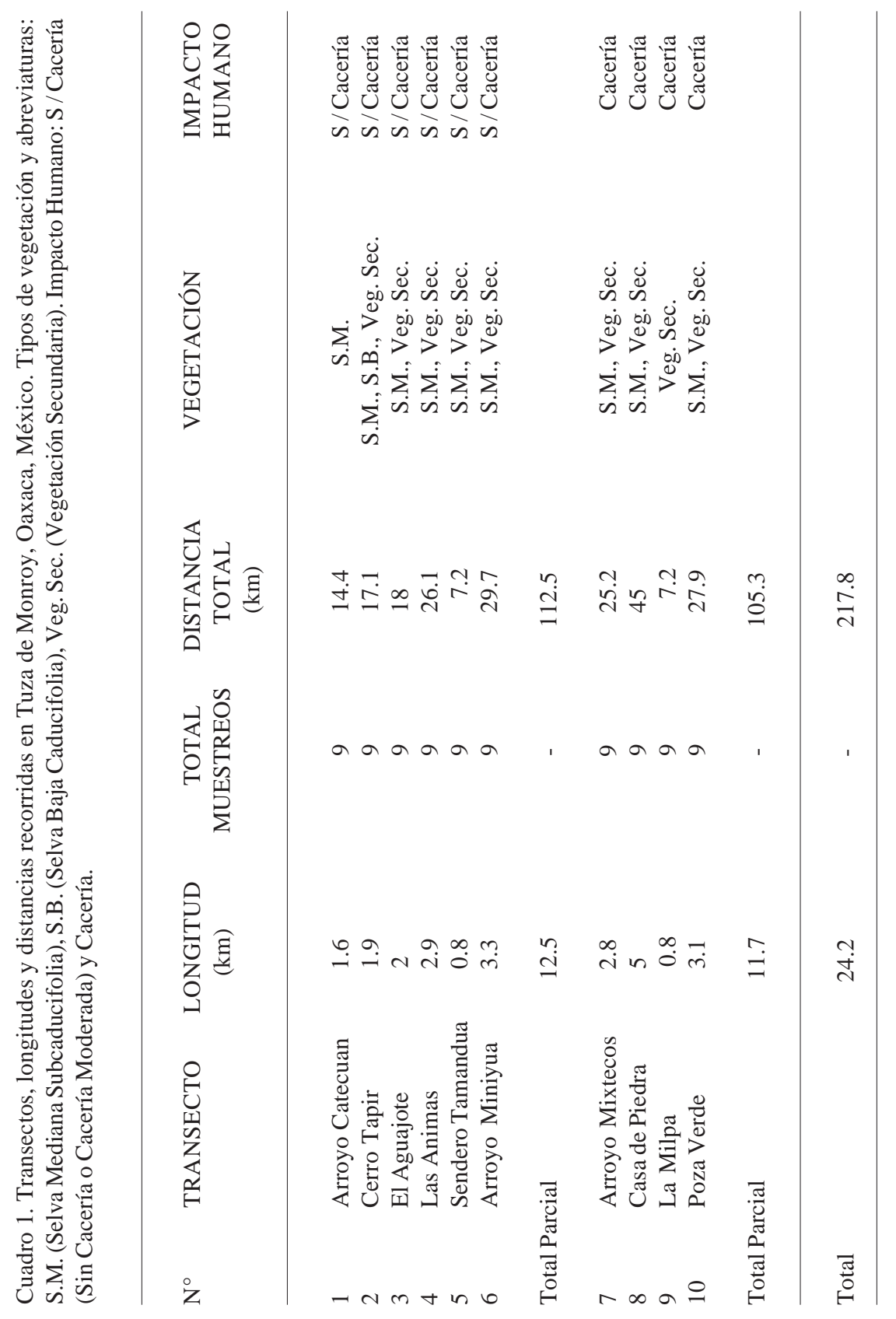




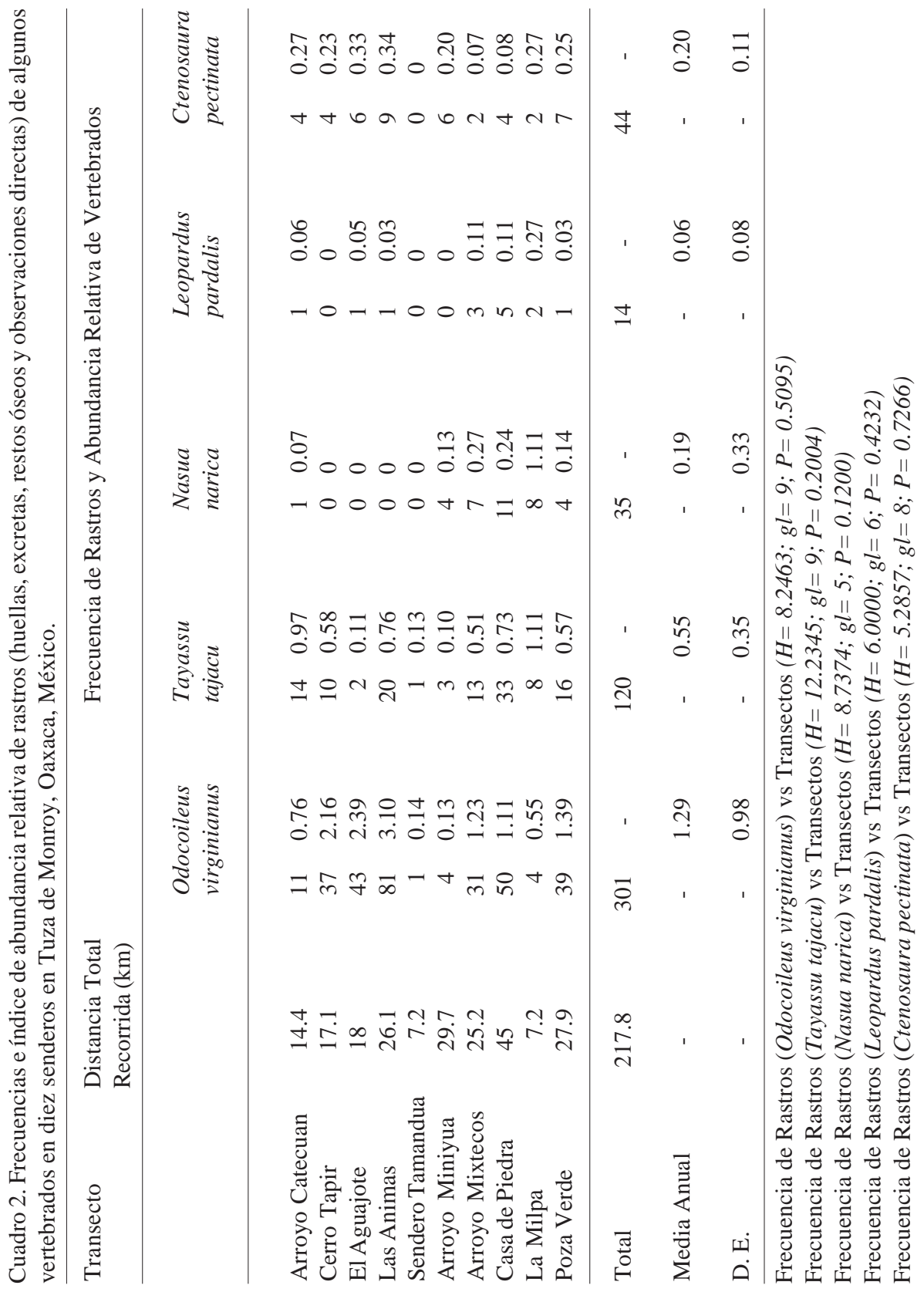




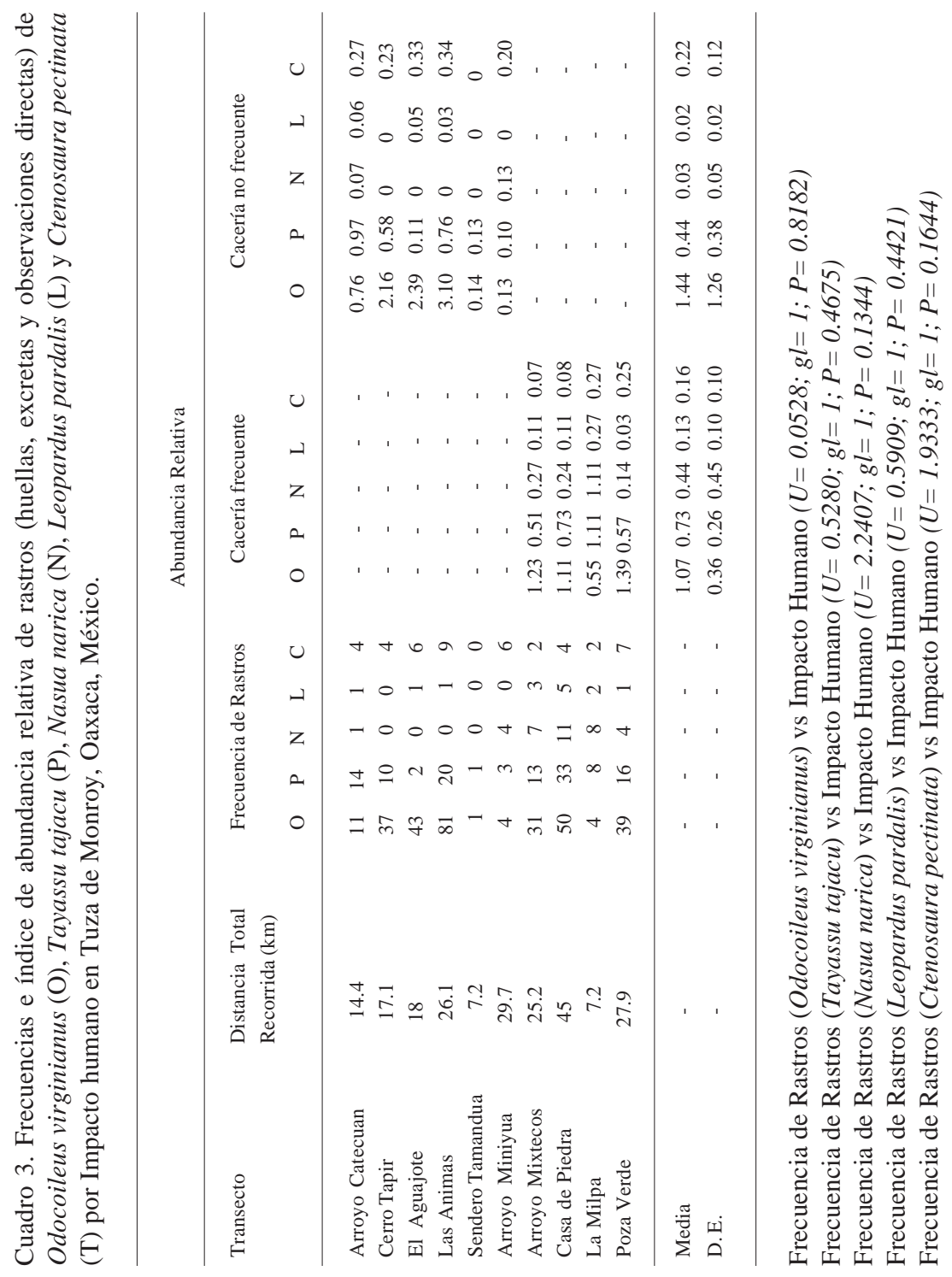


No se encontraron diferencias significativas entre temporadas (lluvias vs seca) para $T$. tajacu $(U=2.3095, \mathrm{gl}=1, P=0.128), N$. narica $(U=0.9758, \mathrm{gl}=1, P=0.323)$, L. pardalis $(U=1.4795, \mathrm{gl}=1, P=0.223)$, C. pectinata $(U=0.4667, \mathrm{gl}=1, P=0.494)$. En contraste la abundancia de $O$. virginianus en temporada de lluvias si es significativamente mayor que en temporada de secas $(U=18.864, \mathrm{gl}=1, P<0.0001)$. Entre meses no hubo diferencias en $T$. tajacu $(H=11.6557, \mathrm{gl}=8, P=0.167)$, L pardalis $(H=9.7500, \mathrm{gl}=7, P=$ $0.203)$ y $C$. pectinata $(H=7.8000, \mathrm{gl}=8, P=0.453)$, excepto en $O$. virginianus ( $H=$ 62.2287, gl= 8, $P<0.0001)$ y $N$. narica $(H=15.8699$, gl $=7, P=0.0263)$.

\section{Densidad poblacional}

Durante el estudio se observaron 18 individuos de O. virginianus, 13 de T. tajacu, 59 de $N$. narica y 44 de $C$. pectinata. La densidad estimada dentro del área de estudio para estas especies fue de $4.33 \pm$ e.e. $1.36,1.98 \pm 1.09,16.93 \pm 8.84$ y $6.87 \pm 1.45 \mathrm{ind} / \mathrm{km}^{2}$, respectivamente (Cuadro 4). Asumiendo estos valores de densidad, se calculó que, para el área de estudio $\left(54.8 \mathrm{~km}^{2}\right)$ existe un tamaño poblacional estimado de 238, 109, 928 y 377 individuos respectivamente y se estimó que para todo el Cerro de la Tuza de Monroy $\left(203 \mathrm{~km}^{2}\right)$ hay 880 individuos de $O$. virginianus, 404 individuos de T. tajacu, 3,437 individuos de $N$. narica y 1,396 individuos de C. pectinata.

\section{Uso vs. disponibilidad de hábitat}

La vegetación secundaria fue significativamente más utilizada que lo esperado por $O$. virginianus ( $\left.x^{2}=328.528, \mathrm{gl}=2, P<0.01\right)$, . tajacu $\left(x^{2}=427.614, \mathrm{gl}=2, P<0.01\right), N$. narica $\left(x^{2}=473, \mathrm{gl}=2, P<0.01\right)$, L. pardalis $\left(x^{2}=77, \mathrm{gl}=2, P<0.01\right)$ y C. pectinata $\left(x^{2}\right.$ $=28.5, \mathrm{gl}=2, P<0.01)$, mientras que la selva mediana fue utilizada conforme a lo esperado por las cinco especies (Cuadros 5).

\section{Uso local de la fauna silvestre}

Se aplicaron 30 entrevistas en la comunidad, 20 de los entrevistados fueron hombres y 10 mujeres. El 43\% de los entrevistados tenían un promedio de edad entre los 30 y 50 años, dedicándose $29.4 \%$ a actividades relacionadas con la agricultura, $29.4 \%$ a la cacería y $19.6 \%$ a la pesca. Las especies más apreciadas por los cazadores fueron $O$. virginianus, T. tajacu, Dasypus novemcinctus y $N$. narica, en tanto que las aves las más aprovechadas son Ortalis leucogaster, Zenaida asiatica y Leptotila verreauxi, en cuanto a reptiles $C$. pectinata e Iguana iguana son los más buscados. De total de los entrevistados $23.3 \%$, 20\% y $26.6 \%$ cazaron principalmente en la milpa, la selva mediana subcaducifolia y el manglar, respectivamente, utilizando escopetas calibre 16, rifles o pistolas calibre 0.22 . Para ellorealizan recorridos de día con o sin perros, 


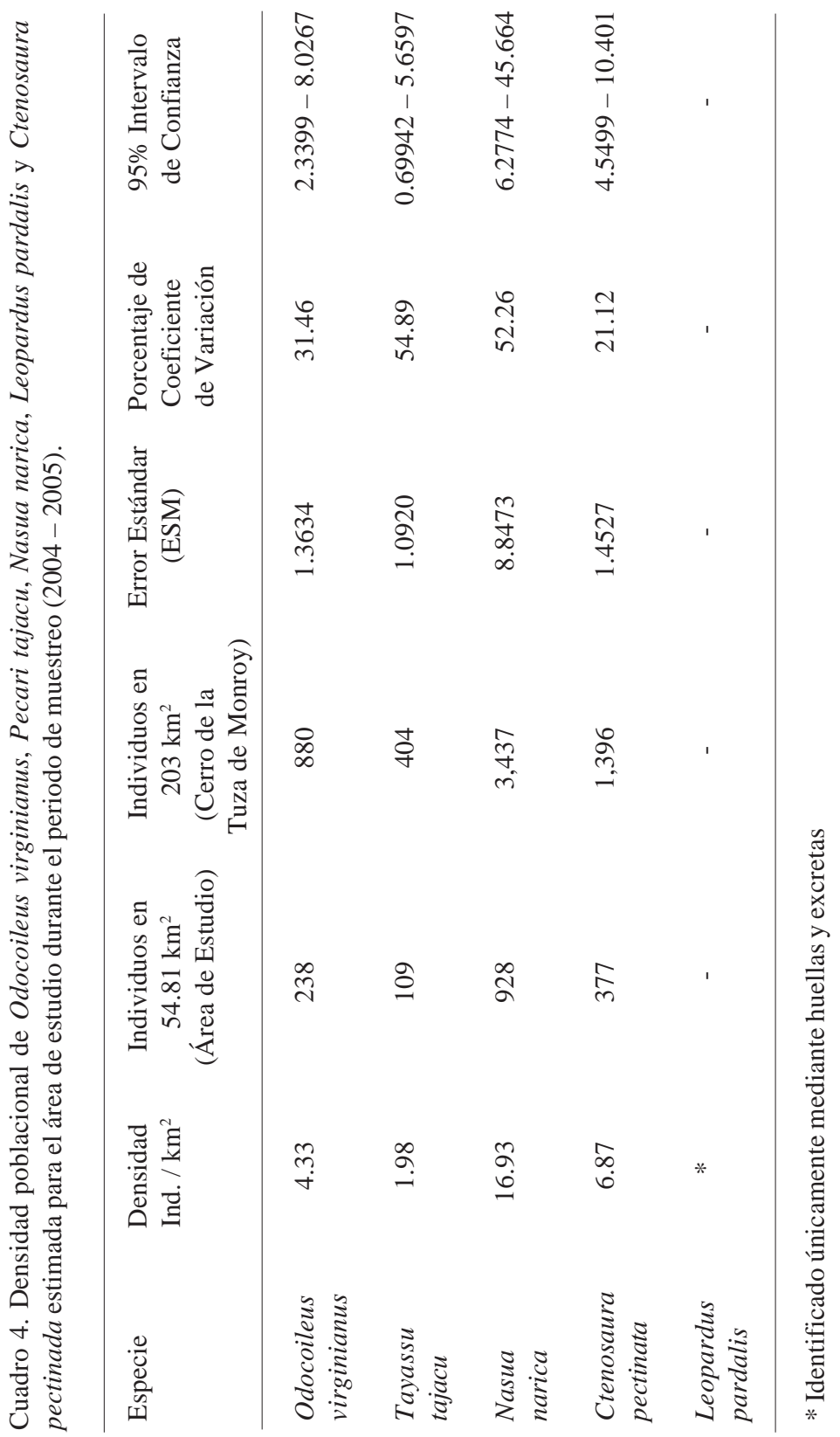


vol. 10

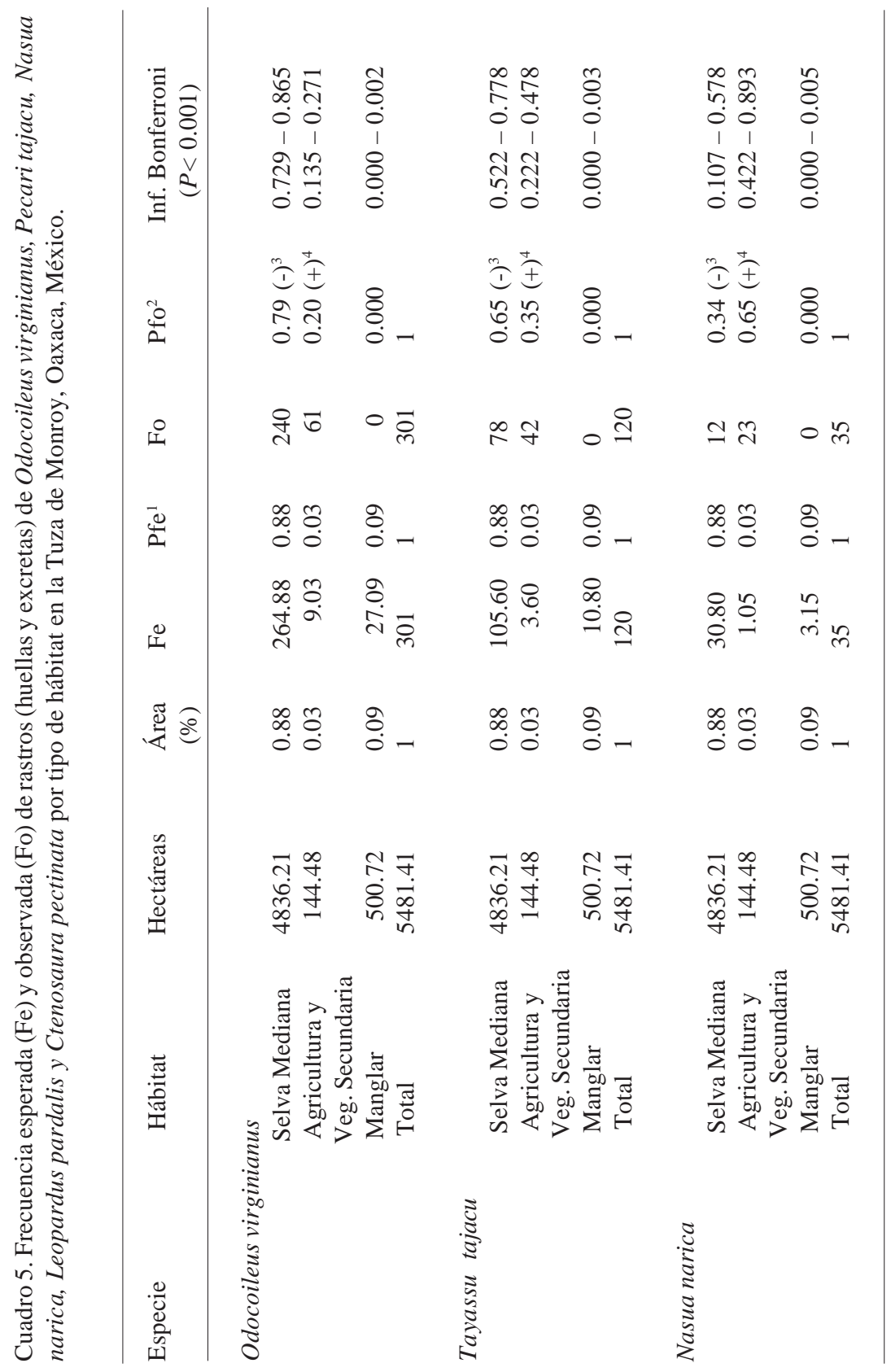




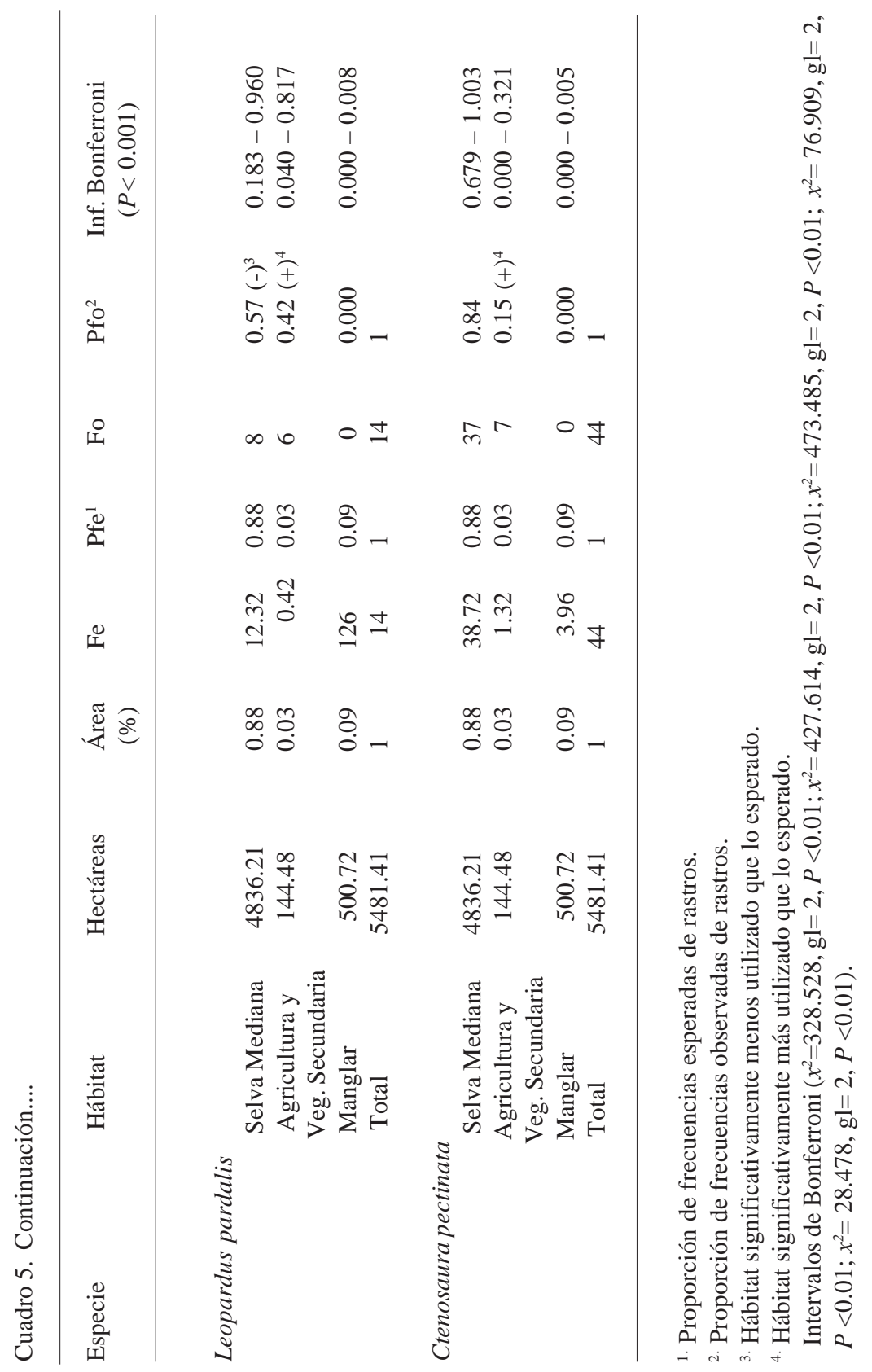


vol. 10

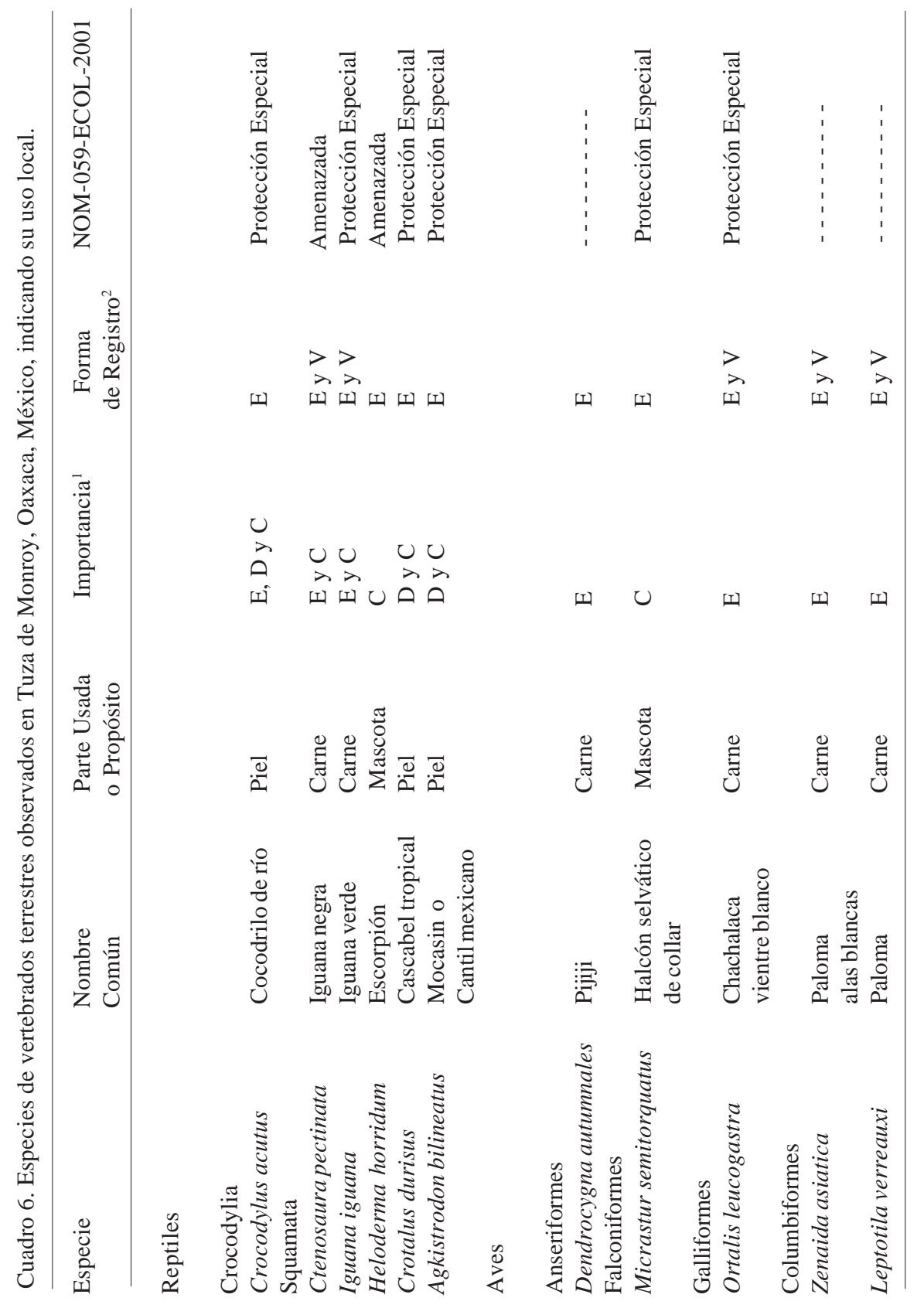




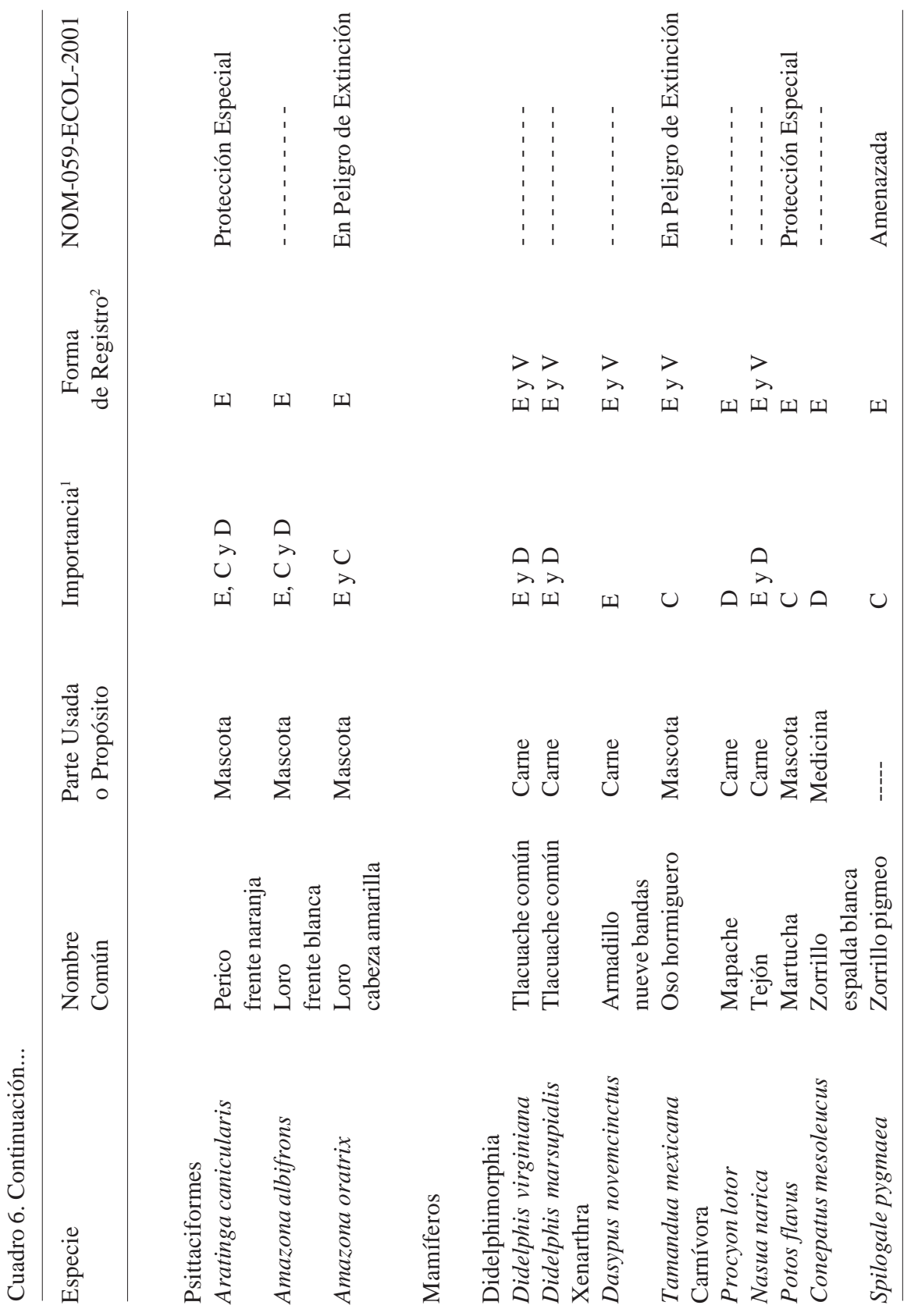




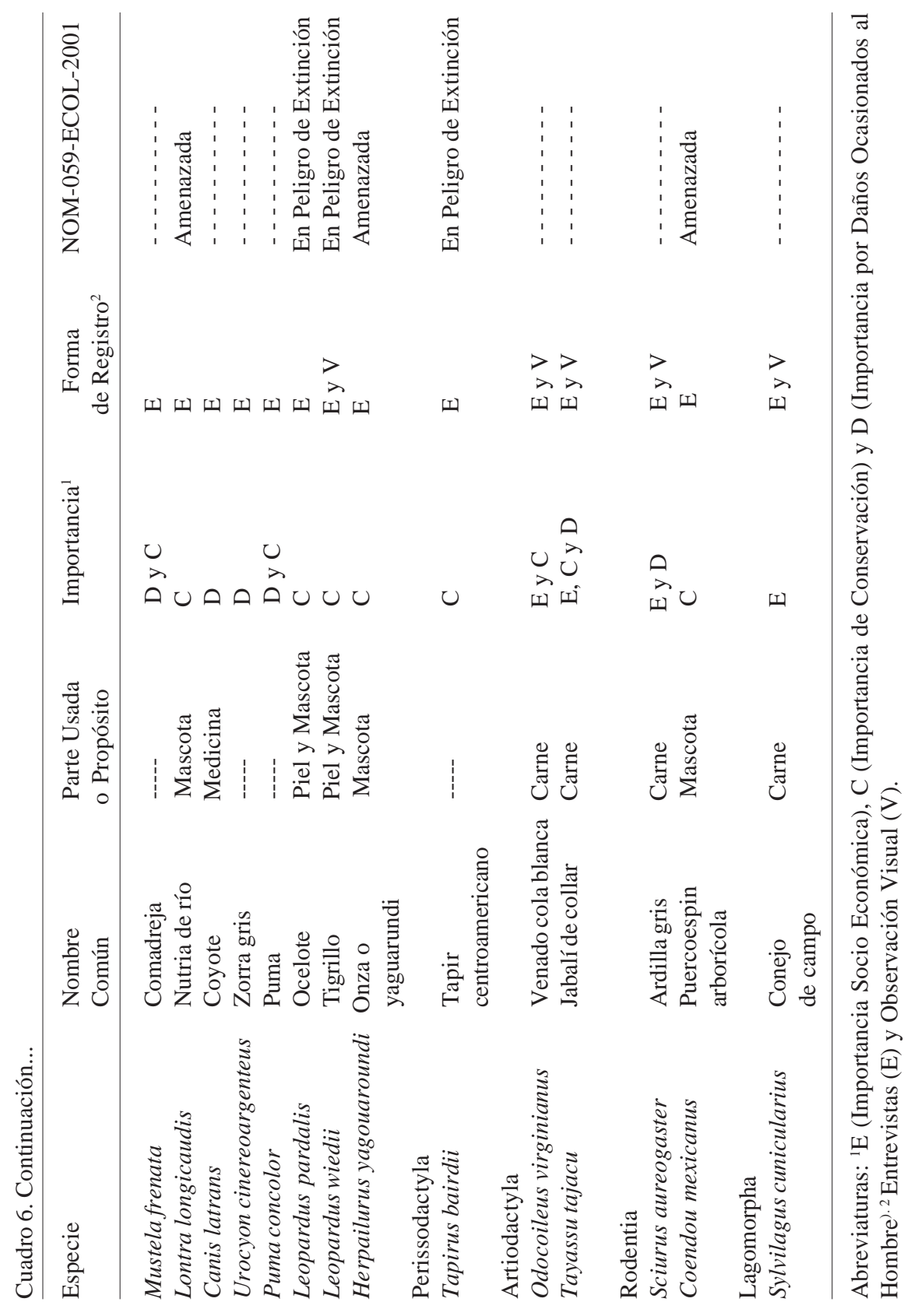


lampareo nocturno y arriadas. La finalidad principal de esta actividad es la obtención de carne y vísceras para consumo, comercialización en la localidad o al exterior. De los cráneos recuperados dos eran juveniles y cuatro adultos para $O$. virginianus, y ocho adultos y cuatro juveniles de T. tajacu.

El total de biomasa extraída para seis especies cazadas por una familia, fue de $588 \mathrm{~kg}$ durante el periodo de estudio. Los mamíferos acumularon 92.2\% del total de la biomasa, en tanto que los reptiles representaron sólo el 7.8\%. Los ungulados constituyeron $79.1 \%$ del total de la biomasa cosechada, seguido por los reptiles (7.5\%), xenarthros (4.8\%), lagomorfos (4.4\%) y carnívoros (4.2\%). Las seis especies con la más alta contribución al total de biomasa cosechada durante el estudio fueron: $N$. narica con tres machos y dos hembras (25 kg de carne), Sylvilagus cunicularius con ocho machos y tres hembras (26 kg), D. novemcinctus con cinco machos y dos hembras (28 kg), C. pectinata con 15 machos y siete hembras (44 kg), O. virginianus con tres machos y dos hembras (210 kg), y T. tajacu con 13 machos y cuatro hembras (255 kg). Al menos 19 especies documentadas durante el estudio y consideradas de importancia para la conservación o desde el punto de vista socioeconómico, se encuentran en alguna categoría de riesgo con base en la NOM-059-SEMARNAT2001, de éstas, seis se encuentran en la categoría de amenazada, ocho en la categoría de protección especial y cinco en peligro de extinción (Cuadro 6).

\section{DISCUSIÓN}

\section{Abundancia relativa}

Los valores máximos correspondieron a O. virginianus, T. tajacu, N. narica, L. pardalis y $C$. pectinata. O. virginianus es una de las especies más estudiada en el país y la subespecie O. virginianus acapulcensis (Hall, 1981), es la que se encuentra en la Tuza de Monroy. Sus ocho subespecies de la región neotropical del país han sido poco estudias y muchas de ellas posiblemente se encuentren en alguna categoría de riesgo (Galindo-Leal y Weber, 1998; Mandujano, 2004).

Odocoileus virginianus juegan un papel clave en la dinámica y estructura de los ecosistemas de la localidad, ya sea por formar parte de la cadena alimentaria como herbívoro, por ser dispersor o depredador de semillas o como especie presa para los carnívoros de la localidad, principalmente para Puma concolor (Ceballos y Miranda, 1986), además de que es una de las especies más adaptable y tolerante a las actividades humanas, como lo es la cacería, persistiendo en la selva mediana subcaducifolia, zonas agrícolas e incluso en los alrededores de la comunidad (Galindo-Leal y Weber, 1998; Mandujano, 2004), siempre y cuando existan reductos de hábitat que brinden alimento, agua y cobertura en cantidad y calidad suficientes. 
Esta situación fue percibida en la localidad estudiada al no encontrarse diferencias entre los índices obtenidos en zonas con cacería recurrente y aquellos con baja intensidad de cacería. Además, se pudo observar durante los recorridos mediante los rastros registrados que esta especie tiene elevados requerimientos de agua durante la época de estiaje, situación que los obliga a trasladarse a los pocos aguajes permanentes que aún existen o a la búsqueda y utilización de otras fuentes de liquido como los árboles de ciruelo (Spondias sp.), empleados por esta especie y otros organismos de la zona como las chacalacas, las iguanas, los jabalíes y los tejones (Mandujano y Martínez Romero, 1997).

Diversos factores influyeron en los índices de abundancia de O. virginianus en la localidad, tales como disponibilidad del alimento, clima, pendientes, parásitos observados en los ejemplares cazados, enfermedades y depredadores, incluyendo al gran número de cazadores que hay en la comunidad y provenientes de otros ejidos (Obs. personal). Trabajos realizados en seis áreas naturales protegidas del Estado de Chiapas, México (Ángel y Cruz, 2004), registran abundancias relativas más bajas de $O$. virginianus que las del presente estudio en diversas localidades: Rabasa tuvo 0.00003 rastros/km, Los Ángeles 0.00004 rastros/km, Región Tiltepec 0.0005 rastros $/ \mathrm{km}$, El Triunfo y Nueva Francia 0.0002, Quetzal 0.00001 rastros/km. Naranjo (2002) registra 0.08 rastros/km y Bolaños (2000) 0.01 rastros / km en la Selva Lacandona. Las bajas abundancias reportadas por estos autores con respecto a las mostradas en el presente estudio, pueden deberse a las diferentes técnicas empleadas y experiencia para monitorear estas especies.

T. tajacu, que ocupó el segundo lugar por su abundancia relativa, tiene una gran habilidad de adaptarse a hábitat fragmentados con presiones de cacería, tal como lo discuten Bodmer y Sowls (1996), Fragoso (1988), March (1990), situación que se afirmó con la ausencia de diferencias significativas en la abundancia relativa. La abundancia registrada de esta especie es mucho mayor a la registrada en otros trabajos realizados en México: Merediz (1995) registra 0.21 rastros/km en la selva mediana subperennifolia de Q. Roo, Quijano (1988) en Tres Reyes, Q. Roo encontró $0.47 \mathrm{rastros} / \mathrm{km}$, en tanto que Bello y Mandujano (1991) encontraron $0.45 \mathrm{rastros} / \mathrm{km}$ en Los Tuxtlas, Ver. Naranjo (2002), por su parte, registró una abundancia relativa de 0.28 rastros/km en la Selva Lacandona, en tanto Lira y Naranjo (2003) 0.13 rastros $/ \mathrm{km}$ en el Polígono I de la Reserva de la Biosfera El Triunfo y Bolaños (2000) 0.55 rastros/km en la Cuenca del río Lacantún. Finalmente Álvarez y Cruz (2004) reportan 0.0007 rastros/ km en la Reserva de la Biosfera Selva El Ocote, Chiapas.

La baja abundancia relativa de $N$. narica y $L$. pardalis, se puede explicar debido a que la observación de carnívoros en libertad comúnmente es un evento poco frecuente debido a que presentan hábitos irregulares y crípticos, es por ello que comúnmente se utiliza el registro de rastros para su estudio en campo (Aranda, 2000; Pardini, et al., 2003). En particular, por su posición en la cima de la pirámide trófica, $L$. 
pardalis es poco abundante (Ceballos, 1990; De Villa Meza et al., 2002). La abundancia obtenida para estas dos especies es mucho menor a la registrada en otros trabajados realizados en México. Naranjo (2002) registro 0.23 y 1.07 rastros/km en la Selva Lacandona, Coates-Estrada y Estrada (1986) reportan 0.33 ind/ha para N. narica en los Tuxtlas, Veracruz. López - González et al., (1995) mencionan índices de 0.27 rastros / km para N. narica y 0.64 rastros / km para L. pardalis en la Estación de Biología Chamela, en la Costa de Jalisco. Por los datos obtenidos se infiere que $N$. narica y $L$. pardalis tienen una baja abundancia en el área de estudio, sin embargo creemos que sus densidades son más altas. $N$. narica, por ejemplo, presenta valores mayores de abundancia en las observaciones directas, lo que indica que el método de huellas subestima la densidad real de esta especie. Esto puede explicarse por el hecho de que $N$. narica en la localidad utiliza más los árboles para desplazarse y sólo bajan para alimentarse (Álvarez del Toro, 1991; Aranda, 2000; Ceballos, 1990; Pardini et al., 2003).

C. pectinata representa un recurso importante en las comunidades rurales como fuente de proteína animal de fácil acceso, lo cual se pudo constatar durante los meses de estudio en esta localidad. Desafortunadamente, el uso excesivo y la destrucción del hábitat de la iguana ha ocasionado que sus poblaciones se hayan reducido drásticamente (Castro-Franco y Bustos, 2003). Los índices de abundancia obtenidos nos muestran una gran habilidad de este reptil para permanecer en sitios moderadamente fragmentados y con presiones de cacería moderadas. La nula información disponible impide comparar los índices obtenidos con otras áreas naturales en todo su rango de distribución.

\section{Densidad poblacional}

Los valores más altos de densidad los registró $N$. narica y los más bajos T. tajacu. La gran abundancia de los tejones está ligada al comportamiento de formar grandes manadas que pueden sobrepasar los 30 individuos (Aranda, 2000; Ceballos y Miranda, 1986).

Los valores de densidad de $O$. virginianus y $T$. tajacu están dentro de los intervalos estimados en otras localidades neotropicales con baja presión de cacería (Alonso, 1997; Branan y Marchinton, 1987; Bodmer et al., 2000; Glanz, 1982; LópezBenítez et al., 2004; López et al., 2004; Mandujano, 1991; Miranda et al., 2004; Pacheco y Montes, 2004; Polisar et al., 1998; Quijano, 1988; Quinto, 1994; Wallace y Painter, 2000).

Esto no es un indicio de que las poblaciones de ambas especies se encuentren en buen estado de conservación, dado que Tuza de Monroy se está aislando por una matriz de pastizales, lo que sugiere que en el futuro la pérdida de hábitat los hará competir más intensamente entre si, lo cual se hace más pronunciando si se toma en cuenta que la zona está alejada de otras zonas con buena cobertura vegetal (Sierra Madre del Sur, Parque Nacional Lagunas de Chacahua). 
Por otro lado, la baja densidad y extinción local de depredadores tope, como $P$. concolor, L. pardalis y Panthera onca conlleva al aumento de densidades de especies de hábitos generalistas (mesopredadores), como N. narica y Procyon lotor, que pueden ocasionar, a su vez, alteraciones drásticas en las comunidades de pequeños vertebrados, además de cultivos (Pardini et al., 2003).

Finalmente, las densidades mostradas por C. pectinata en Tuza de Monroy posiblemente están asociadas a su consumo por las comunidades humanas de la región, lo cual ha sido registrado en el Municipio de Santos Reyes Nopala (Zurita, 1999; Zurita et al., 2004) y en el estado de Morelos (Castro-Franco y Bustos, 2003), lo cual puede poner en riesgo a esta población a largo plazo.

\section{Uso vs. disponibilidad de hábitat}

Generalmente se sabe poco sobre los factores idóneos de un hábitat para una especie en particular. A menudo existe una asociación positiva entre la condición y la calidad del hábitat, pero algunas especies alcanzan su máxima abundancia en áreas degradadas o fragmentadas, tal como fue el caso de $O$. virginianus, $T$. tajacu, $N$. narica y $C$. pectinata. Las causas de fondo de la asociación entre la cobertura vegetal y la abundancia de una especie pueden ser las condiciones microclimáticas, el alimento disponible y otros rasgos elusivos para el observador (Ceballos y Miranda, 1986).

\section{Uso local de la fauna silvestre}

Los principales usos que se le da a la fauna silvestre presente en el área de estudio son en orden de importancia 1) carne de monte (venados, pecarís, armadillos, conejos, tejones, chacalacas, palomas e iguanas); 2) mascotas (aves canoras y de ornato, pequeños carnívoros, serpientes, lagartos y tortugas); 3) pieles (felinos, nutrias, cocodrilos y serpientes, principalmente); y 4) medicina tradicional (serpientes, zorrillos, coyotes y felinos).

Todos los entrevistados aceptaron su gusto por la carne de monte que constituye una de las principales fuentes de proteína animal en la región (GonzálezPérez et al., 2004). En cuanto a las especies más frecuentemente se encuentra $O$. virginianus, T. tajacu, D. novemcinctus, N. narica, O. leucogaster, Z. asiática, L. verreauxi, C. pectinata e I. iguana.

Las causas de su uso frecuente en la localidad de estudio son 1) a excepción de $O$. virginianus y $D$. novemcinctus, la mayoría son de hábitos diurnos, situación que es aprovechada por la mayoría de los cazadores, quienes practican esta actividad de manera "oportunista" cuando encuentran la presa en el camino a sus parcelas o potreros; 2) en el caso de $T$. tajacu, y $N$. narica son las especies que más afectan a los cultivos de maíz, fríjol, calabaza y otros, por lo que su caza además de obtener carne 
para el hogar es un método de control de daños; 3) los usos y costumbres así como la apetecibilidad de algunas carnes, como en el caso de la de $O$. virginianus, de $C$. pectinata y de I. iguana (Castro-Franco y Bustos, 2003; González-Pérez et al., 2004).

En el mercado local y regional del Pacífico oaxaqueño existe el comercio y la actividad extractiva de fauna silvestre porque es tradición comer, vestir, curarse o poseer algo de fauna de las selvas, por ello los animales vivos o sus pieles tienen siempre mercado (González-Pérez et al., 2004). La pobreza, la falta de iniciativa, visión y conflictos étnicos de muchos campesinos de la localidad los ha impulsado a comerciar con la fauna, con lo que obtienen los recursos económicos que les faltan. La cacería de subsistencia está permitida para los campesinos por las autoridades del ejido, obteniendo de esta forma los productos de origen animal que requieren; sin embargo, la población que actualmente tiene la comunidad hace que esta forma de consumo sea a la larga demasiado elevado para ser sostenida por las poblaciones de fauna silvestre (Bodmer y Robinson, 2004). En estas circunstancias, la producción natural de fauna no puede sostener una extracción tan grande, considerando que se entrevistaron a representantes de 30 familias de las 58 que viven en Tuza de Monroy y cada una de ellas consume al año en promedio $588 \mathrm{~kg}$ de carne de monte, por lo que el consumo total en la localidad es de 17,640 kg, sin considerar la que se obtiene para su venta al exterior, lo cual pone en peligro las poblaciones de fauna silvestre. Es importante resaltar que aunque algunas personas poseen bovinos, porcinos y aves de corral, la comunidad escasamente los consume, ya que no es posible conservar la carne en refrigeración o comercializarlas debido al bajo poder adquisitivo de la gente.

La distribución y comercialización de carne de animales silvestres se centra en los restaurantes de Pinotepa Nacional, Zapotalito, Chacahua y Puerto Escondido. La carne se vende a un precio de \$100.00 a \$150.00 pesos por kg de carne de venado y a \$250.00 por ejemplar de iguana. Esta situación fomenta que la gran mayoría de las personas del área se centren en la cacería de animales, lo cual provoca que se impida u obstaculice el acceso a personas ajenas a la comunidad.

No se obtuvieron evidencias de aprovechamiento regular de pieles de pecaríes o de venados. Prácticamente todos los entrevistados comentaron que cuando cazaban un ejemplar de éstos, desechaban la piel o se lo daban a los perros. Esta actividad contrasta con los reportes de Bodmer (1990) quien señala que en Sudamérica las pieles de pecaríes constituyen un rubro importante de exportaciones en países como Argentina, Bolivia y Perú, que exportan anualmente alrededor de 50,000 pieles hacia Alemania, Francia e Italia. De acuerdo con este mismo autor, el valor de cada piel de pecarí que se paga a los cazadores es de 7 a 9 dólares en los países citados, por lo que no debería descartarse la idea de crear en un futuro cercano un mercado regulado de este tipo de pieles en la localidad de Tuza de Monroy donde existen las condiciones adecuadas para ello, tales como poblaciones viables de estos mamíferos, buscar buena disposición de los habitantes locales, y posiblemente de autorregulación efectiva de la cacería y el comercio de las pieles. 
De esto se desprende la siguiente interrogante: si existe tanta demanda de la fauna silvestre y es baja su producción dentro de las poblaciones en condiciones naturales, ¿por qué no producirla en Unidades de Conservación, Manejo y Aprovechamiento Sustentable de la Vida Silvestre intensivas (UMAs), principalmente de especies como las iguanas negras y verdes, el venado cola blanca y los pecaríes de collar? (Bodmer y Robinson, 2004).

Entre otras de las actividades que podrían representar alternativas económica concretas de mediano y largo plazo para la comunidad están también a) buscar el desarrollo del ecoturismo responsable a través de la creación de senderos interpretativos para la observación de aves (psitacidos, rapaces, aves acuáticas), así como la construcción de cabañas y restaurantes regionales para la llegada del turista alternativo; b) incentivar la producción de miel en la comunidad; y c) buscar la posibilidad abrir estacionalmente la barra de la Laguna de Tuza de Monroy, para permitir el resurgimiento de la actividad pesquera en la zona. Estas acciones promoverían el manejo y la conservación de las especies y al mismo tiempo contribuirán al desarrollo de la comunidad en el área de estudio.

\section{AGRADECIMIENTOS}

El autor agradece a la Comisión Nacional de Áreas Naturales Protegidas / Parque Nacional Lagunas de Chacahua (CONANP/ PNLCH), por el apoyo logístico brindado y el financiamiento otorgado. A los pobladores del Ejido de la Tuza de Monroy, Municipio de Santiago Jamiltepec, en especial a la familia Santiago Castro por su hospitalidad y facilidades prestadas para este estudio, y a Idea Wild, por el equipo de campo donado.

\section{LITERATURACITADA}

Álvarez del Toro, M. 1991. Los mamíferos de Chiapas. Gobierno del Estado de Chiapas, México.

Álvarez, V.C. y E. Cruz. 2004. Abundancia de Pecari tajacu Artiodactyla en la Reserva de la Biosfera "Selva El Ocote". P.103, en: Memorias del VII Congreso Nacional de Mastozoología. San Cristóbal de las Casas, Chiapas, México.

Alonso, A.J. 1997. Estado Actual de la Fauna Silvestre en la Propuesta Reserva Comunal del Pucacuro. Pp. 93-103, en: Manejo de Fauna Silvestre en la Amazonía. (Fang T. G., R. E. Bodmer, R. Aquino, y M. Valqui, eds.). Instituto de Ecología, La Paz, Bolivia.

Ángel, C.F.R y E. Cruz. 2004. Abundancia del orden Artiodactyla en seis áreas naturales protegidas de Chiapas, México. P. 104, en: Memorias del VII Congreso Nacional de Mastozoología. San Cristóbal de las Casas, Chiapas, México.

Aranda, M. 2000. Huellas y otros rastros de los mamíferos grandes y medianos de México. Instituto de Ecología A.C., Xalapa, México. 
Arriaga, L., J.M. Espinoza, C. Aguilar, E. Martínez, L. Gómez y E. Loa (coord.). 2000. Regiones terrestres prioritarias de México. Comisión Nacional par el Conocimiento y Uso de la Biodiversidad, México, D.F.

Bello, J. y S. Mandujano. 1992. Distribución y Abundancia Relativa de las Especies del orden Artíodactila en los Tuxtlas Veracruz. Pp.199-211, en: Memorias del X Simposio sobre Fauna Silvestre. Facultad de Medicina Veterinaria y Zootecnia, Universidad Nacional Autónoma de México, México, D.F.

Bodmer, R.E. 1990. Responses of Ungulates to Seasonal Inundations in the Amazonia Floodplain. Journal of Tropical Ecology, 6:191-201.

Bodmer, R.E. y K.L. Sowls. 1996. El Pecarí de Collar. Pp. 5 - 15, en: Plan de Acción y Evaluación de la Condición actual de los Pecaríes. (W. Oliver, ed.). IUCN.

Bodmer, R.E., R. Aquino y J.G.G. Navarro. 2000. Sustentabilidad de la Caza de Mamíferos en la Cuenca del Río Samiria, Amazonía Peruana. Pp. 447-469, en: Manejo de Fauna Silvestre en Amazonía y Latinoamérica. (Cabrera, E., C. Mercolli, y R. Resquin, eds.). Asunción, Paraguay.

Bodmer, R.E. y J.G. Robinson. 2004. Evaluating the Sustainability of Hunting in the Neotropics. Pp. 299-323, en: People in Nature: Wildlife Conservation in South and Central America. (Silvius K. M., R. E. Botmer, and J. M. V. Fragoso, eds.). Columbia University Press / Nueva York, EUA.

Bolaños, J.E. 2000. Densidad, abundancia relativa, distribución y uso local de los ungulados en la Cuenca del Río Lacantún, Chiapas, México. Tesis de Licenciatura. Escuela de Biología, Universidad de Ciencias y Artes del Estado de Chiapas. Tuxtla Gutiérrez, Chiapas, México.

Buckland, S.T., D.R. Anderson, K.P. Burnham, y J.L. Laake. 1993. Distance sampling: estimating abundance of biological populations. Chapman \& Hall, Londres, Reino Unido. 446 p.

Byers, C.R., R.K. Steinhorst y P.R. Krausman. 1984. Clarification of a technique for analysis of utilization-availability data. Journal Wildlife Management, 48: 1050-1053.

Castro-Franco, R. y M.G. Bustos, Z. 2003. Lagartijas de Morelos, México: distribución, hábitat y conservación. Acta Zoologica Mexicana(n.s.), 88:123-42.

Ceballos, G. 1990. Comparative natural history of small mammals from tropical forests in western México. Journal of Mammalogy, 71:263-266.

Ceballos, G. y A. Miranda. 1986. Los Mamíferos de Chamela, Jalisco. Instituto de Biología. Universidad Nacional Autónoma de México.

Coates-Estrada, R. y A. Estrada. 1986. Manual de identificación de campo de los mamíferos de la estación de Biología "Los Tuxtlas". Instituto de Biología. Universidad Nacional Autónoma de México.

De Villa Meza., A., E. Martínez y C. López. 2002. Ocelot (Leopardus pardalis) food habits in a Tropical Deciduous Forest of Jalisco, Mexico. American Midland Naturalist, 148:146154.

Fragoso, J.M. 1988. Home Range and Movement Patterns of White-Lipped Peccary (Tayassu pecari) Herds in the Northern Brazilian Amazon. Biotropica, 30: 458-469.

Furze, B., T. de Lacy y J. Birckhead. 1996. Using methods from the social sciences. 4 in Culture, conservation and biodiversity. The social dimension of linking local level develop- 
ment and conservation through protected areas. John Wiley \& Sons, West Sussex, Reino Unido.

García, E. 1973. Modificaciones al sistema de clasificación climática de Köppen. Instituto de Geografía, Universidad Nacional Autónoma de México.

Glanz, W.E. 1982. The Terrestrial Mammal Fauna of Barro Colorado Island: Censuses and Long - Term Changes. Pp. 455-468, en: The ecology of a Tropical Forest: Seasonal Rhythms and Long-Term Changes. (E.G. Leigh, A. S. Rand y D. M. Windsor, eds.). Smithsonian Institution Press, Washington, D.C., EUA.

Galindo - Leal, C. y M. Weber. 1998. El venado de la Sierra Madre Occidental. EDICUSA y CONABIO, México.

González-Pérez, G., M. Briones-Salas y A.M. Alfaro. 2004. Integración del conocimiento faunístico del estado. Pp. 449-466, en: Biodiversidad de Oaxaca. (A.J. García-Mendoza, M. J. Ordóñez y M. Briones-Salas, eds.). Instituto de Biología, UNAM; Fondo Oaxaqueño para la Conservación de la Naturaleza; World Wildlife Fund, México.

Hall, E.R. 1981. The mammals of North America. Vols. I y, II. John Wiley \& Sons. Nueva York, EUA.

Kirkpatrick, R.D. y L.K. Sowls. 1962. Age determination of the collared peccary by the tooth replacement pattern. Journal of Wildlife Management, 26:214-217.

Laurance W.F., y R.O. Bierregaard, Jr. 1997. Tropical forest remnants: Ecology, management, and communities. University of Chicago Press, Chicago.

Lira, I., E. Naranjo, P., D. Güiris, A. y E. Cruz. 2004. Ecología del Tapirus bairdii (Perissodactyla: Tapiridae) en La Reserva de La Biosfera "El Triunfo" (Polígono I), Chiapas, México. Acta Zoologica Mexicana (n.s.), 20: 1-21.

Lira, T.I. y E. Naranjo P. 2003. Abundancia, preferencia de hábitat e impacto del ecoturismo sobre el puma y dos de sus presas en la Reserva de la Biosfera El Triunfo, Chiapas, México. Revista Mexicana de Mastozoología, 7:21-40.

Lira, T.I., E. Naranjo y M. Chargoy. 2005. Ampliación del área de distribución de Tapirus bairdii Gill 1865 (Perisodactila: Tapiridae) en México. Acta Zoologica Mexicana (n.s.), 21:107-110.

López-González, C.A., J. Laundré, W.K. Altendorf y A. Gonzáles-Romero. 1995. Carnivores in a tropical dry forest of western Mexico: test of methods. Annual meeting Northwest Scientific Association and Idaho Chapter, The Wildlife Society. Marzo 9 -11 Idaho Falls, Idaho.

López-Benítez, J.C., G. Yanes y T. López, M.C. 2004. Densidad poblacional del venado cola blanca (Odocoileus virginianus mexicanus) en la UMA Tlalhuayan, Chiautla de Tapia, Puebla. P. 59, en: Memorias del VII Congreso Nacional de Mastozoología. San Cristóbal de las Casas, Chiapas. México.

López, T.M., S. Mandujano y G. Yanes. 2004. Densidad poblacional del venado cola blanca (Odocoileus virginianus mexicanus) en cuatro localidades del municipio de Jolalpan, Puebla. Pp. 60, en: Memorias del VII Congreso Nacional de Mastozoología. San Cristóbal de las Casas, Chiapas, México.

Mandujano, S. 1991. Notas sobre el pecarí de collar en el bosque tropical caducifolio de Chamela, Jalisco. Pp. 222-228, en: Memorias IX Simposio sobre Fauna Silvestre. Facultad de Medicina Veterinaria y Zootecnia, Universidad Nacional Autónoma de México. México. 
Mandujano, S. 2004. Análisis bibliográfico de los venados en México. Acta Zoologica Mexicana(n.s.), 20:211-251.

Mandujano, S. y L.E. Martínez-Romero. 1997. Fruit fall caused by chachalacas (Ortalis poliocephala) on red mombim trees (Spondias purpurea): impact on terrestrial fruit consumers, especially the white-tailed deer (Odocoileus virginianus). Studies on Neotropical Fauna and Environment, 31:1-3.

March, I. J. 1990. Evaluación del Hábitat y Situación Actual del Pécari de Labios Blancos Tayassu pecari en México. Tesis de Maestría. Programa Regional en Manejo de Vida Silvestre para Mesoamérica y el Caribe. Universidad Nacional Heredia, Costa Rica.

Miranda, A.,G. Ambriz., y B. Vázquez. 2004. Densidad poblacional, área de actividad y movimientos del Pecarí de Collar (Tayassu tajacu) en la Reserva de la Biosfera ChamelaCuixmala, Jalisco, México y su área de influencia. Pp. 104, en: Memorias del VII Congreso Nacional de Mastozoología. San Cristóbal de las Casas, Chiapas, México.

Naranjo, E.J. 2000. Estimaciones de abundancia y densidad en poblaciones de fauna silvestre tropical. Pp. 37-46, en: Manejo de Fauna Silvestre en Amazonía y Latinoamérica. (Cabrera, E., C. Mercolli, y R. Resquin, eds.). Asunción, Paraguay.

Naranjo, E.J. 2002. Population Ecology and Conservation of Ungulates in the Lacandon Forest, Mexico. Doctoral dissertation. Florida University, EUA.

Naranjo, E.J., M. Guerra, M., R.E. Bodmer y J.E. Bolaños. 2004. Subsistence Hunting by Three Ethnic Groups of the Lacandon Forest, México. Journal of Ehnobiology, 24:233253.

Quijano, E. 1988. Distribución, Abundancia y Conocimiento Tradicional de Mamíferos Silvestres: Bases para la Creación de un Plan de Manejo y Aprovechamiento en Tres Reyes, Quintana Roo. Tesis de Licenciatura en Biología. Universidad Nacional Autónoma de México. México.

Quinto, F. 1994. Estudio sobre la Distribución y Abundancia del Jabalí de Collar en Ejidos Forestales de Quintana Roo. en: Memorias del XII Simposio sobre Fauna Silvestre. Facultad de Medicina Veterinaria y Zootecnia, Universidad Nacional Autónoma de México.

Ojasti, J. 2000. Manejo de Fauna Silvestre Neotropical. F. Dallmeir (ed.). Smithsonian Institution y MAB Program, Washington, D.C., EUA.

Pacheco, S.G.J. y P. Montes, R. 2004. Densidad y distribución del pecarí de collar (Pecari tajacu, Linnaeus 1758) en el Municipio de Tzucaban, Yucatán, México. Pp. 64, en: Memorias del VII Congreso Nacional de Mastozoología. San Cristóbal de las Casas, Chiapas, México.

Pardini, R., E.H. Ditt., L. Cullen., C. Bassi y R. Rudran. 2003. Levantamento rápido de mamíferos terretres de médio e grande porte. Pp. 181-201, en: Métodos de Estudo em Biología da Conservacao Manejo da Vida Silvestre. (Cullen, L., R. Pudran y C. ValladaresPadua, eds.) Ed. da. UFPR; Fundacao O Boticario de Protecao a Natureza. Curitiba, Paraná, Brazil.

Polisar, J., R. McNab, M., H. Quigley, M.J. González y M. Cabrera. 1998. A Preliminary Assesment of the Effects of Subsistence Hunting in the Maya Biosphere Reserve. Informe al WCS, Flores Petén, Guatemala. Inédito.

Robinson, J.G., y E.L. Bennett (eds.). 2000. Hunting for sustainability in tropical forest. Columbia University Press, Nueva York, EUA. 
Rzedowski, J. 1998. Diversidad y orígenes de la flora fanerogámica de México. Pp. 129- 145, en: Diversidad Biológica de México. Orígenes y Distribución (T.P. Ramamoorthy, R. Bye, A. Lot y J. Fa, eds.). Instituto de Biología, UNAM, México.

SEMARNAT, Secretaría de Medio Ambiente, Recursos Naturales y Pesca. 2002. Norma Oficial Mexicana NOM-059-ECOL-2000. Protección ambiental, especies de flora y fauna silvestres de México, categorías de riesgo y especificaciones para su inclusión, exclusión o cambio, y lista de especies en riesgo. Diario Oficial de la Federación, 1:1-62.

SAS Institute. 1994. SAS/STAT user's guide. Relase 6.08 Edition. SAS Institute Inc., Cary NC, EUA.

Shaw, J.H. 1991. The outlook for sustainable harvests in Latin America. en: Neotropical wildlife use and conservation. (J. G. Robinson y K. H. Redford,eds.). University of Chicago Press, Chicago.

Thomas, L., J.L. Laake, S. Strindberg, F.F.C. Marques, S.T. Buckland, D.L. Borchers, D.R. Anderson, K.P. Burnham, S.L. Hedley, J.H. Pollard, J.R.B. Bishop, y T.A. Marques. 2005. Distance 5.0. Research Unit for Wildlife Population Assessment, University of St. Andrews, Reino Unido. http://www.ruwpa.st-and.ac.uk/distance/

Wallace, R.B. y R.L. Painter. 2000. Conservación de pecaríes en la Amazonía Boliviana: Biodiversidad vs viabilidad poblacional. Pp 263-271, en: Manejo de Fauna Silvestre en Amazonía y Latinoamérica. (E. Cabrera, C. Mercolli, y R. Resquin, eds.). Asunción, Paraguay.

Zurita, C.M.E. 1999. Situación actual de la iguana negra (Ctenosaura pectinata) en el municipio de Santos Reyes Nopala, Oaxaca. Tesis de Licenciatura. Departamento de Suelos, Universidad Autónoma Chapingo, Montecillos, Estado de México.

Zurita, C.M.E., B. Valdez, A. González, G. Mendoza, y J. Arcos. 2004. Densidad poblacional y composición de la dieta de la iguana negra (Ctenosuara pectinata) en el Municipio de Santos Reyes Nopala, Oaxaca. Pp. 83-91, en: Memorias de la VII Reunión sobre Iguanas en México. Universidad del Mar. Mazatlán, Sinaloa. 